\title{
Caregiving burden and its determinants in Polish caregivers of stroke survivors
}

\author{
Krystyna Jaracz ${ }^{1}$, Barbara Grabowska-Fudala ${ }^{1}$, Krystyna Górna ${ }^{1}$, Wojciech Kozubski ${ }^{2}$
}

${ }^{1}$ Department of Neurological and Psychiatric Nursing, Poznan University of Medical Sciences, Poznan, Poland

${ }^{2}$ Department of Neurology, Poznan University of Medical Sciences, Poznan, Poland

Submitted: 19 July 2012

Accepted: 18 November 2012

Arch Med Sci 2014; 10, 5: 941-950

DOI: 10.5114/aoms.2014.46214

Copyright $\odot 2014$ Termedia \& Banach

\author{
Corresponding author: \\ Krystyna Jaracz \\ Department of Neurological \\ and Psychiatric Nursing \\ Poznan University \\ of Medical Sciences \\ 11 Smoluchowskiego St \\ 60-179 Poznan, Poland \\ Phone: +48616559267 \\ E-mail: jaracz@ump.edu.pl
}

\begin{abstract}
Introduction: Despite the growing body of literature on the consequences of providing non-professional care to stroke survivors, the determinants of caregiving burden are still not fully recognized. Identification of significant determinants can facilitate caregiver intervention programs. The aim of this study was to evaluate the level of burden borne by caregivers of stroke patients and to identify the most important determinants of burden at 6 months after hospitalization.

Material and methods: Data were collected from 150 pairs of stroke patients/caregivers. Caregiver burden was assessed on the Caregiver Burden scale (CB). Several characteristics were measured as potential predictors of the burden. Special attention was paid to the caregiver's sense of coherence (SOC) and anxiety. Regression analysis was employed to test the hypothesized relationships between these variables and the burden.

Results: Forty-seven percentage of the caregivers reported a substantial burden (severe or moderate). Caregiver SOC $(p<0.001)$, anxiety $(p<0.001)$ and the patients' functional status $(p<0.001)$ were the most important predictors of the overall burden and the most consistent predictors of the majority of aspects included in the CB scale. Caregiver health, patient's gender, time spent caregiving and social support were also factors related to the burden. The identified predictors explained $67 \%$ of the variance in the overall burden.

Conclusions: Clinicians and other professionals should focus on the coping abilities of caregivers, their emotional state and the level of patients' dependency, as these are the vital and modifiable factors affecting caregiver burden following stroke.
\end{abstract}

Key words: stroke, family caregiving, stress, coping.

\section{Introduction}

Despite advances in the treatment of the acute phase, stroke remains a leading cause of death and long-term disability among adults around the world [1-3]. As a disease of an ageing society, the global prevalence of stroke survivors will increase, reaching an estimated 77 million by 2030 [4]. According to the World Health Organization, about 15 million people suffer from a stroke annually, of whom $1 / 3$ die, and another $1 / 3$ are left permanently disabled [5]. In Poland approximately 60,000 people suffer from a stroke each year, that is $0.16 \%$ of the general population 
[6]. Most stroke survivors return home immediately after discharge from hospital, and their care is taken over by the family or other close people. More than half of the patients experience various impairments and disabilities [7, 8].

Caring for stroke patients, especially disabled ones, may be a source of chronic stress due to the gap between caregiving demands and the physical, psychological and financial resources of the caregivers, all of which may lead to the serious negative consequences referred to in the literature as "caregiving strain" or "burden" $[9,10]$. Previous studies have shown that, on average, the caregiver burden following stroke is moderate. In most reports the mean scores in various measurements did not exceed the $50^{\text {th }}$ percentile in their theoretical scope [11-15]. Nevertheless, the percentage of persons experiencing substantial strain in the first year after stroke was estimated at $25 \%$ to $54 \%$ [16]. The variability of the level of burden depends on a variety of factors related to both the patient's and the caregiver's characteristics. Among the most frequently identified factors are: the patient's functional status $[11,12,17-21]$, the caregiver's depressive symptoms $[13,18,20]$, the time spent caregiving or the number of caregiving tasks $[12,18,21]$ and the caregiver's social support [13, 22]. In the majority of reports the proportion of explained variance in burden $\left(R^{2}\right)$ did not exceed 0.5 $[13,18,20]$. This indicates that there is a place for identifying other significant determinants which should be considered when developing strategies to alleviate caregiver problems. Two such factors that have rarely been taken into consideration are caregiver sense of coherence (SOC) and anxiety.

Antonovsky defined SOC as an individual's ability to cope successfully and confidently with stress through mobilizing all the appropriate internal and external resources [23]. In this context it may be assumed that SOC is an important positive predictor of the burden. To our knowledge there are only two reports [24, 25] from the same large ongoing study that focused specifically on the relationships between SOC as an explanatory variable and caregiver burden after stroke as an outcome variable. The authors concluded that a strong SOC plays a protective role against the burden. In addition, several studies concerning associations between the caregivers' SOC and concepts similar to burden, such as quality of life, well-being, burn-out and mental health, have been published [26-29].

Anxiety is a physiological reaction to stress. However it can be harmful when it becomes prolonged. Prevalence of anxiety among carers of stroke patients has been reported as high (up to 58\%) [30] and, according to some authors, it is higher than depression [31-33]. Nevertheless, few studies have focused on the association between burden of care and anxiety symptoms, and these have shown that anxiety is an independent factor affecting the burden within the first year after stroke $[13,20]$. Most of the research on caregiving following stroke has been conducted in western Europe or in the USA [16, 34]. This is the first such study carried out in Poland.

The general aim of the study was to better understand the caregiver burden during the first months after discharge from hospital. The specific aims were: (1) to evaluate the severity of burden experienced by caregivers, (2) to identify the best predictors of caregiver burden from the characteristics of the patients, and (3) to identify the best predictors of caregiver burden from the characteristics of the caregivers, focusing especially on the sense of coherence and emotional status.

\section{Material and methods}

\section{Design and procedure}

The present work is part of a larger project conducted in our research departments which examines caregiving for individuals following a stroke $[35,36]$. We used a non-experimental prospective, cross-sectional design in which the participants were assessed at 2 different time points: time 1 , during the patients' hospitalization, and time 2, 6 months after discharge. This design allowed us to measure and describe the burden, in terms of subjective and multidimensional phenomena, as well as to gather simultaneously data on several explanatory variables which might be important from the clinical stand point. The 6 months' time frame was selected because the functional status of stroke patients usually stabilizes within the first 6 months following the stroke, which simultaneously is the most difficult time for caregivers [37].

During the first examination, the socio-demographic characteristics of the patients and their caregivers, as well as data on the background medical and clinical status of the patients, were collected. During the second assessment, data on caregiver burden and its potential predictors, as well as on the patients' neurological and functional status, were gathered. The second assessment was performed at the participants' home. All the participants gave their voluntary informed consent. The study was approved by the Poznan Bioethics Committee of the University of Medical Sciences.

\section{Study sample}

The study participants were patient/primary caregiver pairs consecutively admitted to the Neurological Department of Wielkopolska Province Hospital in Poznan, Poland. This is a multi-profile hospital providing specialist comprehensive 
inpatient medical service to the inhabitants of Wielkopolska, a geographical region situated in the north-west of Poland with a population of approximately three and a half million [38]. The population of Wielkopolska, as with the country as a whole, is homogeneous in race and ethnicity; $97 \%$ of people are of Polish nationality.

Inclusion criteria for the patients were: age above 18 years and a diagnosis of first-ever stroke. The exclusion criteria were: recurrent stroke, presence of an additional illness and/or prestroke disability which required persistent patient help, alcohol or drug dependence, functional recovery before hospital discharge (Barthel Index > 14 points), and discharge to an institution other than home. The final sample consisted of 80 men and 70 women, all of Polish origin, with a mean age of 64 years (standard deviation, SD $=12.7$ ), median = 63 (range: $21-95$ ). The women were significantly older than the men: median $=71$ years vs. 59 years, $p<0.001$. Inclusion criteria for the caregivers were: being a spouse/partner, parent, adult child, other significant family member or friend who lived with the patient or was in close contact several times per week, directly involved in the patient's care, and lacking previous experience in providing care for a chronically ill family member. The exclusion criterion was: being a professional or paid caregiver. The final sample consisted of 124 women and 26 men, all of Polish origin, with a mean age of 53.5 years (SD $=13.8)$; median 55 (range: 18-85). No significant difference in age between male and female caregivers was found. Detailed characteristics are shown in Table I.

\section{Measurement tools}

\section{Assessment of caregivers}

The Caregiver Burden scale (CB) was used to assess the burden. This scale consists of 22 items which can be separated into five subscales [39]. The range of scores was from 1 to 4 . A score of 1.00-1.99 indicated a low burden, 2.00-2.99 a moderate and 3.00-4.00 a high burden. Our study was the first to use the CB scale in Poland. The English version of the instrument provided by Sölve Elmståhl was translated into Polish by two native Polish experts in the English language, and then back-translated into English by another two native Polish language experts. An expert committee was involved in reaching final agreement on both translations. The Cronbach's $\alpha$ reliability coefficient for the scale used in the current study was 0.9 , which was similar to that for the original instrument (Cronbach's $\alpha$ 0.9) [39].

The Hospital Anxiety and Depression Scale (HADS) was used to detect depression and anxiety [40]. A score of 11 or more on the HADS-Anxiety
Table I. Socio-demographic characteristics of the caregivers

\begin{tabular}{|c|c|c|}
\hline Characteristics & Number & Percentage \\
\hline \multicolumn{3}{|l|}{ Gender: } \\
\hline Male & 26 & 17.0 \\
\hline Female & 124 & 83.0 \\
\hline Age, mean (SD) [years] & \multicolumn{2}{|c|}{$53.51(13.85)$} \\
\hline \multicolumn{3}{|l|}{ Relationship: } \\
\hline Spouse & 86 & 57.0 \\
\hline Child & 38 & 25.0 \\
\hline Sibling & 7 & 5.0 \\
\hline Parents & 3 & 2.0 \\
\hline Distant relatives or friend & 16 & 11.0 \\
\hline \multicolumn{3}{|l|}{ Education: } \\
\hline Primary & 30 & 20.0 \\
\hline Vocational & 49 & 33.0 \\
\hline Secondary school & 52 & 34.0 \\
\hline University & 19 & 13.0 \\
\hline \multicolumn{3}{|l|}{ Working status: } \\
\hline Active & 55 & 36.7 \\
\hline Non-active & 95 & 63.3 \\
\hline \multicolumn{3}{|l|}{ Living arrangement status: } \\
\hline Living with the patient only & 44 & 29.0 \\
\hline $\begin{array}{l}\text { Living with the patient } \\
\text { and/or with others }\end{array}$ & 106 & 71.0 \\
\hline $\begin{array}{l}\text { Time providing care daily, } \\
\text { mean (SD) }[\mathrm{h}]\end{array}$ & \multicolumn{2}{|c|}{$8.32(6.10)$} \\
\hline
\end{tabular}

and HADS-Depression subscales denoted anxiety or depression. Antonovsky's Sense of Coherence scale (SOC-29) was used to measure the carers' global life orientation [23]. The possible total score ranged from 29 to 203 and, for descriptive purposes, it was divided by tertiles into weak (29-87), moderate (88-145) and strong (146-203). The Berlin Social Support Scale (BSSS) was used to assess the amount of emotional, informational and instrumental support received by the caregivers [41]. Total scores ranged from 15 to 60. One single item of the World Health Organization Quality of Life-BREF (WHOQOL-BREF) was applied to assess an overall perception of health, namely "How satisfied are you with your health?" Responses were rated on a 5-point Likert scale [42]. A structured questionnaire was used to gather the clinical data of the patients and the socio-demographic data of both the patients and the caregivers. 


\section{Assessment of patients}

The Scandinavian Stroke Scale (SSS) and the Barthel Index (BI) were used to assess the neurological and functional status, respectively. These tools are popular instruments in neurology with well-established psychometric properties $[43,44]$.

The Dynamic Assessment of Aphasia Scale was applied to assess the communicative ability of the patients [45]. The short form of the Geriatric Depression Scale (GDS) was used as a screening measure of depressive symptoms. This scale was originally established for people more than 55 years old, but it has also been used in younger in- dividuals while retaining satisfactory psychometric properties $[25,46,47]$.

\section{Statistical analysis}

Descriptive statistics of the variables are presented as percentages, mean, median and standard deviation (SD). Changes in the neurological and functional status of the stroke patients were assessed by the Wilcoxon test and McNemar's tests. Bivariate analyses were applied to assess relationships between caregiver burden and patient/ caregiver characteristics and to select variables for inclusion in the multivariate analyses (Table II). Pearson's $r$ correlation coefficient was used to

Table II. Candidate predictor variables for caregiver's burden. Bivariate analysis $(p \leq 0.10)$

\begin{tabular}{|c|c|c|c|c|c|c|}
\hline Characteristics & Burden total & $\begin{array}{l}\text { General } \\
\text { strain }\end{array}$ & $\begin{array}{c}\text { Disappoint- } \\
\text { ment }\end{array}$ & $\begin{array}{c}\text { Emotional } \\
\text { involvement }\end{array}$ & Isolation & Environment \\
\hline \multicolumn{7}{|l|}{ Patient: } \\
\hline $\begin{array}{l}\text { Gender (median: } \\
\text { male vs. female) }\end{array}$ & 2.02 vs. 1.77 & 2.25 vs. 2.0 & 2.40 vs. 1.80 & 1.66 vs. 1.33 & NS & NS \\
\hline $\mathrm{Age}^{\mathrm{a}}$ & NS & 0.17 & NS & NS & 0.20 & NS \\
\hline $\mathrm{SSS}^{\mathrm{a}}$ & -0.47 & -0.48 & -0.44 & NS & -0.37 & -0.24 \\
\hline $\mathrm{Bl}^{\mathrm{a}}$ & -0.55 & -0.54 & -0.41 & -0.19 & -0.45 & -0.37 \\
\hline $\begin{array}{l}\text { Depression } \\
\text { (median: yes vs. no) }\end{array}$ & 2.0 vs. 1.81 & 2.12 vs. 2.0 & 2.20 vs. 2.0 & 1.66 vs. 1.33 & NS & 1.66 vs. 1.33 \\
\hline $\begin{array}{l}\text { Speaking difficulties } \\
\text { (median: yes vs. no) }^{b}\end{array}$ & NS & NS & 2.60 vs. 2.0 & NS & NS & NS \\
\hline \multicolumn{7}{|l|}{ Caregiver: } \\
\hline Age $^{\mathrm{a}}$ & 0.17 & 0.16 & 0.16 & NS & 0.19 & NS \\
\hline $\begin{array}{l}\text { Relationship } \\
\text { (median: spouses vs. } \\
\text { not spouses) }\end{array}$ & 2.0 vs. 1.79 & NS & 2.40 vs. 1.80 & NS & NS & NS \\
\hline $\begin{array}{l}\text { Living arrangement } \\
\text { (median: living } \\
\text { with the patient } \\
\text { only vs. other living } \\
\text { arrangement) }^{\mathrm{b}}\end{array}$ & 2.09 vs. 1.86 & 2.37 vs. 2.0 & 2.40 vs. 2.10 & NS & 2.16 vs. 1.66 & NS \\
\hline $\begin{array}{l}\text { Working status } \\
\text { (median: active vs. } \\
\text { not active) }{ }^{\mathrm{b}}\end{array}$ & 1.86 vs. 1.95 & 1.87 vs. 2.25 & 2.0 vs. 2.20 & NS & NS & NS \\
\hline $\begin{array}{l}\text { Presence of diseases } \\
\text { (median: yes vs. no) }\end{array}$ & 2.05 vs. 1.72 & 2.37 vs. 1.81 & 2.20 vs. 2.0 & NS & 2.0 vs. 1.33 & NS \\
\hline $\begin{array}{l}\text { Self-assessment } \\
\text { of health }^{\mathrm{a}}\end{array}$ & -0.35 & -0.38 & -0.32 & -0.31 & -0.20 & NS \\
\hline HADS-anxiety ${ }^{a}$ & 0.60 & 0.55 & 0.53 & 0.39 & 0.47 & 0.21 \\
\hline HADS-depression ${ }^{a}$ & 0.57 & 0.54 & 0.48 & 0.44 & 0.43 & 0.19 \\
\hline BSSS $^{a}$ & -0.26 & -0.25 & -0.18 & -0.30 & -0.23 & NS \\
\hline SOC $-29^{a}$ & -0.65 & -0.56 & -0.57 & -0.53 & -0.47 & -0.29 \\
\hline $\begin{array}{l}\text { Hours spent helping } \\
\text { per day }\end{array}$ & 0.38 & 0.36 & 0.38 & 0.18 & 0.18 & 0.24 \\
\hline
\end{tabular}

aPearson correlation coefficient, ${ }^{b}$ Mann-Whitney U test. NS - nonsignificant, SD - standard deviation, SSS - Scandinavian Stroke Scale, BI - Barthel Index, HADS - Hospital Anxiety and Depression Scale, BSSS - Berlin Social Support Scale, SOC - Sense of Coherence Scale 
analyze relationships between burden and continuous variables. Taking into account the skewness, the results were additionally checked with the Spearman rank correlation coefficient. Both measures showed similar results. Correlation coefficient values were considered as small, medium or large, expressing weak, moderate and strong relationships when their values were below 0.3 , from 0.3 to 0.49 , and 0.5 and above, respectively. It should be noted that a weak relationship means that the analyzed variables share a small amount of variance and, because of that, despite their statistical relevance, their practical significance might be relatively weak [48].

The Mann-Whitney $U$ test was used to examine the relationships between burden and dichotomous variables. Stepwise multiple regression analysis was used to identify independent predictors of burden, taking into account the total CB and its five indices (subscales) scores as dependent variables. Since the sample size was 150 , and there was a large number of potential explanatory variables, we entered in the regression analysis those patient/caregiver characteristics that were significantly correlated with at least one subscale in the bivariate analysis $(p<0.10)$.

Residual analyses and collinearity diagnostics were carried out to verify the basic assumptions of the regression. If necessary, a logarithmic transfor- mation of the dependent variable was performed. The analyses were conducted with Statistica StatSoft 9 software (StatSoft Polska, Kraków, Poland).

\section{Results}

\section{Patients' clinical characteristics}

At 6 months after stroke, most patients had improved significantly in their neurological and functional status. However, $8 \%$ of the patients still presented severe stroke impairment and 15\% demonstrated very severe or severe functional dependence. Depressive symptoms were present in $43 \%$ of the subjects (Table III). There were no significant differences in neurological status, functional status or depression level between men and women. Also, no significant correlations were observed between age and neurological status and depression. Only a weak relationship was found for age and functional status at time $2(r=-0.21$; $p<0.05)$.

\section{Caregivers' characteristics and burden}

The mean HADS-Depression and HADS-Anxiety scores were relatively low. However, one fifth of the caregivers had depressive symptoms, and one third had symptoms of anxiety. The mean SOC-29 value indicates that, on average, the caregiver's SOC was moderate. The BSSS mean score demonstrates

Table III. Clinical characteristics of the stroke patients at discharge and after 6 months

\begin{tabular}{|c|c|c|c|}
\hline Characteristics & Discharge & 6-month follow-up & Value of $p$ \\
\hline \multicolumn{4}{|l|}{ Neurological status (SSS): } \\
\hline Mean (SD) (range 0-58 bad-good) & $29.33(11.15)$ & $46.13(10.35)$ & - \\
\hline Median & 30.0 & 48.0 & $<0.001^{\mathrm{a}}$ \\
\hline Very severe/severe impairment (range: 0-29), $n$ (\%) & $73(49.0)$ & $12(8.0)$ & - \\
\hline Moderate/mild impairment (range: $30-58), n(\%)$ & $77(51.0)$ & $138(92.0)$ & - \\
\hline \multicolumn{4}{|l|}{ Functional status (BI): } \\
\hline Mean (SD) (range 0-20/bad-good) & $4.33(4.11)$ & $14.73(5.45)$ & - \\
\hline Median & 2.0 & 16.0 & $<0.001^{a}$ \\
\hline Very severe/severe disability (range: $0-9$ ), $n(\%)$ & $129(86.0)$ & $23(15.0)$ & - \\
\hline Moderate/mild disability (range: 10-20), $n$ (\%) & $21(14.0)$ & $127(85.0)$ & - \\
\hline \multicolumn{4}{|l|}{ Depressive mood $(G D S)^{*}$ : } \\
\hline Yes (range: $2-4), n(\%)$ & - & $65(43.0)$ & - \\
\hline No (range: $0-1), n(\%)$ & - & $85(57.0)$ & - \\
\hline \multicolumn{4}{|l|}{ Speaking difficulties: } \\
\hline Yes $-n(\%)$ (range: $0-8)$ & $43(29.0)$ & $41(27.0)$ & $0.479^{b}$ \\
\hline No $-n(\%)(>8)$ & $107(71.0)$ & $109(73.0)$ & \\
\hline
\end{tabular}

${ }^{\star} G D S$ assessed at 6 months only, ${ }^{a}$ Wilcoxon test, ${ }^{b}$ McNemar's test, SSS - Scandinavian Stroke Scale, SD - standard deviation, BI - Barthel Index, GDS - Geriatric Depression Scale 
that, on average, caregivers received high social support. The mean WHOQOL score reflects moderate satisfaction with their own health (Table IV). The mean total CB score was $2.08(S D=0.6)$. Nearly half of the caregivers experienced a moderate or severe burden. The highest burden was noted in General strain and Disappointment, the lowest in the Environmental subscale (Table V).

There were no significant differences in SOC, BSSS, HADS-Depression/Anxiety, or WHOQOL between men and women. Also there were no significant correlations of those variables with age, except for a weak relationship of age with HADSDepression $(r=0.24 ; p<0.05)$ and WHOQOL $(r=$ $-0.24 ; p<0.05)$.

\section{Association between patient/caregiver characteristics and the caregivers' total and subscale burden scores}

Variables that were significantly related to the CB scores $(p \leq 0.10)$ are displayed in Table II. There were 5 patient and eleven caregiver characteristics that were associated with the total score and/ or at least with one subscale. Strong correlations with the total score were observed for SOC, caregiver anxiety, depression, and patient's functional status. Moderate correlations were seen for the patient's neurological status and for time spent caregiving. Weak correlations were noted for caregiver social support and age. A similar distribution of the coefficient levels was found in the subscales, although the strength of the relationships was generally weaker. Additional analyses showed significant correlations between SOC and anxiety $(r=0.63, p<0.001)$, SOC and depression $(r=0.62$, $p<0.001)$ and between SOC and social support $(r=-0.43, p<0.001)$.

Table IV. Means and standard deviations on self-reported variables for stroke caregivers

\begin{tabular}{|c|c|}
\hline Scales & Mean (SD) \\
\hline \multicolumn{2}{|c|}{ Hospital Anxiety and Depression Scale: } \\
\hline $\begin{array}{l}\text { Depression subscale } \\
\text { (range: 0-21/good-bad) }\end{array}$ & $5.51(4.90)$ \\
\hline Score $\geq 11, n(\%)$ & $27(18.0)$ \\
\hline $\begin{array}{l}\text { Anxiety subscale } \\
\text { (range: } 0-21 / \text { good-bad) }\end{array}$ & $8.57(4.71)$ \\
\hline Score $\geq 11, n(\%)$ & $49(33.0)$ \\
\hline $\begin{array}{l}\text { Sense of Coherence Scale } \\
\text { (range: } 29-203 / \text { bad-good) }\end{array}$ & $141.06(26.99)$ \\
\hline $\begin{array}{l}\text { Berlin Social Support Scale } \\
\text { (range: } 15-60 / \text { bad-good) }\end{array}$ & $50.83(12.85)$ \\
\hline $\begin{array}{l}\text { Self-assessment of health } \\
\text { (range } 1-5 / \text { bad-good) }\end{array}$ & $3.41(0.96)$ \\
\hline
\end{tabular}

SD - standard deviation
The significant correlates of the caregiver burden were selected to identify their unique contributions to regression models. Stroke impairment was not included because of its high correlation (collinearity) with functional disability $(r=0.81)$. The caregiver's SOC and anxiety and the patient's functional status were found to be the strongest predictors of the total burden, which explained $67 \%$ of its variance, together with the patient's gender and the caregiver's morbidity. The three aforementioned variables were also predictors for three out of four CB subscales. Together with the other seven variables, they explained $35-60 \%$ of the variance in the CB subscales (Table VI). Environment was not used in the analysis because the residuals were not normally distributed and a log transformation was not effective.

\section{Discussion}

Stroke not only has direct consequences in the form of physical and psychological impairment of the patient, but also results in a burden for the caregivers, which may constitute a significant health concern reducing the quality of care provided to the loved ones $[9,10]$. The findings reported here provide evidence that caregiver strain is a multidimensional phenomenon, influenced both by factors on the part of the patient as well as on the part of the caregiver. This indicates the need for professional intervention aimed at both improving post-hospital stroke outcomes and improving caregiver's well-being.

The first specific aim of our study was to evaluate the severity of burden borne by caregivers of stroke patients. The results showed that almost one half of the caregivers (47\%) experienced significant strain. In comparison with similar Europe-

Table V. Caregiver Burden scale scores in stroke caregivers

\begin{tabular}{|c|c|}
\hline $\begin{array}{l}\text { CB scale (total and subscale score } \\
\text { range } 0-4 / \text { good-bad) }\end{array}$ & Result \\
\hline Total burden, mean (SD): & $2.08(0.65)$ \\
\hline Low burden, $n(\%)$ & $80(53.0)$ \\
\hline Moderate burden, $n(\%)$ & $52(35.0)$ \\
\hline Severe burden, $n(\%)$ & $18(12.0)$ \\
\hline General strain, mean (SD) & $2.27(0.81)$ \\
\hline Disappointment, mean (SD) & $2.28(0.84)$ \\
\hline Emotional involvement, mean (SD) & $1.68(0.85)$ \\
\hline Isolation, mean (SD) & $1.92(0.93)$ \\
\hline Environment, mean (SD) & $1.79(0.78)$ \\
\hline
\end{tabular}


Table VI. Predictors of caregiver's burden. Multiple regression analysis $(p \leq 0.05)$

\begin{tabular}{|c|c|c|c|c|c|}
\hline Burden & Predictors & Stand. $\beta$ & Value of $t$ & Value of $p$ & Adj. $R^{2}$ \\
\hline \multirow[t]{5}{*}{ Total score } & Sense of coherence & -0.43 & -7.04 & $<0.001$ & \multirow[t]{5}{*}{0.67} \\
\hline & Functional status & -0.35 & -6.98 & $<0.001$ & \\
\hline & Anxiety & 0.23 & 3.72 & $<0.001$ & \\
\hline & Patients' gender (male) & 0.14 & 2.84 & 0.005 & \\
\hline & Presence of diseases (yes) & 0.12 & 2.47 & 0.015 & \\
\hline \multirow[t]{5}{*}{ General strain } & Functional status & -0.38 & -6.93 & $<0.001$ & \multirow[t]{5}{*}{0.60} \\
\hline & Sense of coherence & -0.28 & -4.13 & $<0.001$ & \\
\hline & Anxiety & 0.24 & 3.52 & 0.001 & \\
\hline & Presence of diseases (yes) & 0.16 & 2.90 & 0.004 & \\
\hline & Health self-assessment & -0.15 & -2.59 & 0.010 & \\
\hline \multirow[t]{6}{*}{ Disappointment } & Sense of coherence & -0.38 & -5.03 & $<0.001$ & \multirow[t]{6}{*}{0.56} \\
\hline & Patients' gender (male) & 0.23 & 3.94 & $<0.001$ & \\
\hline & Hours spent helping per day & 0.20 & 3.09 & 0.002 & \\
\hline & Anxiety & 0.19 & 2.65 & 0.009 & \\
\hline & Functional status & -0.18 & -2.69 & 0.008 & \\
\hline & Patients' age & -0.14 & -2.36 & 0.02 & \\
\hline \multirow{3}{*}{$\begin{array}{l}\text { Emotional } \\
\text { involvement* }\end{array}$} & Sense of coherence & -0.49 & -6.86 & $<0.001$ & \multirow[t]{3}{*}{0.35} \\
\hline & Health self-assessment & -0.15 & -2.11 & 0.036 & \\
\hline & Patients' gender (male) & 0.14 & 2.08 & 0.039 & \\
\hline \multirow[t]{4}{*}{ Isolation } & Anxiety & 0.37 & 5.75 & $<0.001$ & \multirow[t]{4}{*}{0.41} \\
\hline & Functional status & -0.34 & -5.06 & $<0.001$ & \\
\hline & Social support & -0.16 & -2.33 & 0.021 & \\
\hline & Living arrangement (with the patient only) & 0.14 & 2.06 & 0.041 & \\
\hline
\end{tabular}

Stand. $\beta$-standardized $\beta$, Adj. $R^{2}$ - Adjusted $R^{2}$. ${ }^{\star}$ The emotional involvement subscale score was logarithmically transformed.

an studies carried out at 6 months after stroke, this proportion is relatively high. The relevant figures for Norway, Netherlands, Belgium and Scotland are $25 \%, 30 \%, 29 \%$, and $37 \%$, respectively $[11,12,16,49]$. These discrepancies may reflect, on the one hand, methodological differences between the studies, but may also indicate differences in caregiving support systems in Europe. The EUROFAMCARE study showed that carers' use of support services is generally limited throughout Europe, but in Poland it is noticeably worse than in Germany, Sweden, and the UK. In most western European countries more than $20 \%$ of caregivers use a support service, while in Poland fewer than $5 \%$ do so [50].

The next aim of this work was to identify independent determinants of caregiver burden in terms of the total CB score and the subscale scores among key factors known from the literature, together with less frequently analyzed variables, such as caregiver's sense of coherence and anxiety. Our findings show that one of the most important factors that have been strongly correlated and most consistently associated with burden is the sense of coherence. Caregivers with a stronger SOC reported lower levels of burden in the total CB scale and in the majority of subscales controlling for other variables. These findings support Antonovsky's SOC theory and corroborate research by Chumbler et al. [24] and van Puymbroeck et al. [25] that point to a positive role of SOC in alleviating the sequelae of psychological distress. The results of the correlation analysis concerning SOC in the present study, together with the findings of other investigations based on SOC theory $[23,25,29$, 35], allow us to speculate that the positive effect of SOC on caregiver burden might occur as a protection against depression and anxiety, as well as through mobilizing social support. However, this framework should be further explored in a lon- 
gitudinal study, in different phases of the stroke process and caregiving. Nevertheless, our data indicate the need for professional interventions to reduce stress, develop skills to deal with stressful situations and protect or strengthen individual inner coping resources. This type of intervention includes psycho-social programs based on information, learning skills and emotional support, as stressed in a recent review by Garces et al. [51].

Another highly important predictor of caregiver burden in this study was anxiety, which was present in a third of the participants. As has been shown in the literature, increased anxiety during the first few months of caregiving may stem from uncertainty about the patient's condition, about leaving the patient alone, fear of the next stroke, and uncertainty about the future $[32,52]$. In the wake of this and other authors' results $[13,20$, $21]$, we can conclude that among the two emotional expressions of psychological distress, namely depression and anxiety, the latter seems to be predominant in the first months of caregiving. This hypothesis could partially explain the lack of a significant contribution of depression to the variance of burden. Nevertheless, greater recognition of the emotional state of the caregivers is required. Also, there is a need for more longitudinal studies to investigate co-occurrence and interdependence between anxiety and depression since, as has been shown by Cooper et al. [53], interventions taken for depressive symptoms may not automatically reduce anxiety. Moreover, because both depression and anxiety were found to be inversely associated with SOC, there is a need for a further longitudinal investigation of these relationships.

In the current study, patient physical disability was the third most important factor related to the caregiver's burden. This is in line with several previous reports $[11,12,17-21]$ and indicates the importance of long-term efforts to foster the patient's physical independence on the one hand, and to teach the caregivers how best to perform basic and instrumental care tasks on the other.

There were other significant determinants of the burden, although they were less consistent within the entire CB scale. One was caregiver health status, operationalized as self-evaluation of health and the presence or absence of diseases. In accordance with our predictions, those in poorer health reported a higher burden. This is in line with similar research by Choi-Kwon et al. [18], who found that caregiver self-rated health status was associated with burden score, but only on one out of three sub-domains analyzed. Other less consistent predictors of increased burden in our study were socio-demographic variables, such as the living arrangement (living with the patient only), younger age of the patient, patient's gender (men) and larger amount of time providing care. Interestingly, providing care for a man was related to higher Total Burden and Disappointment and Emotional involvement scores than caring for a woman. This may be related to loss of income resulting from the man having to give up his job. In the literature, findings about socio-demographic characteristics are highly inconsistent. For example, female caregivers have frequently been seen as more burdened than men [16], but this was not confirmed in our study. Contrary to our expectations, social support was not among the most important determinants of the total burden. However, it did have a predictive value for the Isolation subscale. We can hypothesize that such factors as reciprocity, family conflicts and balance in caregiving between the primary caregiver and other family members may also play a role. In addition, it is possible that the caregivers need more time to fully accept help from others [52].

A few limitations of this research need to be mentioned. First, the study group did not include caregivers of those patients who were in a good functional state before discharge and those who died after discharge. This may limit the representativeness of the sample and therefore the generalisability of the findings. The reasons for including only patients who were moderately or severely affected at the time of discharge was that we had planned the study to capture the experience of caregivers connected with the necessity of providing care in activities of daily living (ADL). Nevertheless, at 6-month follow-up the patients were differentiated according to their functional status.

Second, the cross-sectional and regression-correlation model of the study did not allow us to draw definite conclusions about the cause-effect type of relationship between the burden and its determinants. However, it has been the first stage of our study which is being continued, and we hope that in the longer term, after another follow-up, it will be possible to determine the direction of relationships between the key research variables better.

Third, cognitive and neurobehavioural changes in the stroke patients were not considered in this study although they are frequently observed after stroke and may affect caregivers' well-being $[49,54]$. We did not include these factors as our study focused mainly on the role of a caregiver's SOC and emotional status in the presence of other, previously known predictors of the burden. However, further studies evaluating independent relationships between the behavioral and cognitive status of the patients and caregiver strain are needed. Nevertheless, with these limitations in mind, we hope that this study makes a contri- 
bution to increasing knowledge on caregiver burden, reinforces the findings of other authors, and sheds some new light on modifiable predictors of the burden, especially on the caregivers' psychological characteristics.

In conclusion, this study showed that a substantial proportion of non-professional caregivers experienced a moderate or severe level of burden. Clinicians and other professionals should focus on the coping abilities of caregivers, their emotional state and their patients' dependency, as these are the vital and modifiable factors affecting the burden of care following stroke. Future research should assess simultaneously the trajectories of post-stroke recovery, psychological distress and the caregiving process, and investigate the significance of both protective and harmful factors at different periods following a stroke.

\section{Acknowledgments}

This study was financially supported by the Polish Ministry of Health (grant number N404 073 32/2200). We thank Professor Geoffrey Shaw for his English editing of this text.

\section{References}

1. Roger VL, Go AS, Lloyd-Jones DM, et al. Heart Disease and Stroke Statistics-2012 Update: a report from the American Heart Association. Circulation 2012; 125: e2-220.

2. Mukherjee D, Patil CG. Epidemiology and the global burden of stroke. World Neurosurg 2011; 76: 85-90.

3. Siebert J, Gutknecht P, Molisz A, Trzeciak B, Nyka W. Hemodynamic findings in patients with brain stroke. Arch Med Sci 2012; 8: 371-4.

4. Strong K, Mathers C, Bonita R. Preventing stroke: saving lives around the world. Lancet Neurol 2007; 6: 134-9.

5. McKay J, Mensah GA, Mendis S, Greenlund K. The atlas of heart disease and stroke. World Health Organization (WHO); Geneva 2004.

6. Schinwelski M, Stawek J. Prevalence of spasticity following stroke and its impact on quality of life with emphasis on disability in activities of daily living. Systematic review. Neurol Neurochir Pol 2010; 44: 404-11.

7. Wolfe CD. The impact of stroke. Br Med Bull 2000; 56: 275-86.

8. Skibicka I, Newada M, Skowrońska M, Członkowska A, Członkowski A. Care for patients after stroke. Results of two-year prospective observational study from mazowieckie provinse in Poland. Neurol Neurochir Pol 2010; 44: 231-7.

9. Carretero S, Garcés J, Ródenas F, Sanjosé V. The informal caregiver's burden of dependent people: theory and empirical review. Arch Gerontol Geriatr 2009; 49: 74-9.

10. Perkins M, Howard VJ, Wadley VG, et al. Caregiving strain and all-cause mortality: evidence from the REGARDS Study. J Gerontol B Psychol Sci Soc Sci 2013; 68: 504-12.

11. Ilse IB, Feys H, de Wit L, Putman K, de Weerdt W. Stroke caregivers' strain: prevalence and determinants in the first six months after stroke. Disabil Rehabil 2008; 30: 523-30.

12. Van Exel NJ, Koopmanschap MA, van den Berg B, Brouwer WB, van den Bos GA. Burden of informal caregiving for stroke patients. Identification of caregivers at risk of adverse health effects. Cerebrovasc Dis 2005; 19: 11-7.

13. McCullagh E, Brigstocke G, Donaldson N, Kalra L. Determinants of caregiving burden and quality of life in caregivers of stroke patients. Stroke 2005; 36: 2181-6.

14. Suh M, Kim K, Kim I, Cho N, Choi H, Noh S. Caregiver's burden, depression and support as predictors of poststroke depression: a cross-sectional survey. Int I Nurs Stud 2005; 42: 611-8.

15. Evci ED, Ergin F, Saruhan G, et al. Prevalence and predictors of burden among family caregivers of the elderly in a Western City in Turkey: a community-based, cross-sectional study. J Med Med Sci 2012; 3: 569-77.

16. Rigby H, Gubits G, Philips S. A systematic review of caregiver burden following stroke. Int J Stroke 2009; 4: 285-92.

17. Visser-Meily A, Post M, Schepers V, Lindeman E. Spouses' quality of life 1 year after stroke: prediction at the start of clinical rehabilitation. Cerebrovasc Dis 2005; 20: 443-8.

18. Choi-Kwon S, Kim HS, Kwon SU, Kim JS. Factors affecting the burden on caregivers of stroke survivors in South Korea. Arch Phys Med Rehabil 2005; 86: 1043-8.

19. Ferri CP, Schoenborn C, Kalra L, et al. Prevalence of stroke and related burden among older people living in Latin America, India and China. J Neurol Neurosurg Psychiatry 2011; 82: 1074-82.

20. Carod-Artal FJ, Coral LF, Trizotto DS, Moreira MC. Burden and perceived health status among caregivers of stroke patients. Cerebrovasc Dis 2009; 28: 472-80.

21. Vincent C, Desrosiers J, Landreville P, Demers L; BRAD group. Burden of caregivers of people with stroke: evolution and predictors. Cerebrovasc Dis 2009; 27: 456-64.

22. Cumming TB, Cadilhac DA, Rubin G, Crafti N, Pearce DC; the SCOPES II Study Group. Psychological distress and social support in informal caregivers of stroke survivors. Brain Impair 2008; 9: 152-60.

23. Erikkson M, Lindström B. Validity of Antonovsky's sense of coherence scale - a systematic review. J Epidemiol Community Health 2005; 59: 460-6.

24. Chumbler NR, Rittman M, Van Puymbroeck M, Vogel WB, Qin H. The sense of coherence, burden, and depressive symptoms in informal caregivers during the first month after stroke. Int J Geriatr Psychiatry 2004; 19: 944-53.

25. Van Puymbroeck M, Hinojosa MS, Rittman MR. Influence of sense of coherence on caregiver burden and depressive symptoms at 12 months poststroke. Top Stroke Rehabil 2008; 15: 272-82.

26. Perrin PB, Heesacker M, Hinojosa SM, Uthe CE, Rittman MR. Identifying at-risk, ethnically diverse stroke caregivers for counselling: a longitudinal study of mental health. Rehabil Psychol 2009; 54: 138-49.

27. Chumbler NR, Rittman MR, Wu SS. Associations in sense of coherence and depression in caregivers of stroke survivors across 2 years. J Behav Health Serv Res 2008; 35: 226-34.

28. Van Puymbroeck M, Rittman MR. Quality-of-life predictors for caregivers at 1 and 6 months poststroke: results of path analyses. J Rehabil Res Dev 2005; 42: 747-60.

29. Nilsson I, Axelsson K, Gustafson Y, Lundman B, Norberg A. Well-being, sense of coherence, and burnout in stroke victims and spouses during the first few months after stroke. Scand I Caring Sci 2001; 15: 203-14.

30. Wilz G, Kalytta T. Anxiety symptoms in spouses of stroke patients. Cerebrovasc Dis 2008; 25: 311-5. 
31. Smith LN, Norrie J, Kerr SM, Lawrence IM, Langhorne P Lees KR. Impact and influences on caregiver outcomes at one year post-stroke. Cerebrovasc Dis 2004; 18: 145-53.

32. Greenwood N, Mackenzie A. An exploratory study of anxiety in carers of stroke survivors. J Clin Nurs 2010; 19: 2032-8.

33. Balhara YP, Verma R, Sharma S, Mathur S. A study of predictors of anxiety and depression among stroke patient-caregivers. J Midlife Health 2012; 3: 31-5.

34. Gaugler JE. The longitudinal ramifications of stroke caregiving: a systematic review. Rehabil Psychol 2010; 55: 108-25.

35. Jaracz K, Grabowska-Fudala B, Kozubski W. Caregiver burden after stroke: towards a structural model. Neurol Neurochir Pol 2012; 46: 224-342.

36. Grabowska-Fudala B, Jaracz K, Górna K. The burden of caregivers of patients after stroke - preliminary results of prospective evaluation. Nowiny Lekarskie 2012; 81: 3-9.

37. King RB, Semik PE. Stroke caregiving: difficult times, resource use, and needs during the first 2 years. J Gerontol Nurs 2006; 32: 37-44.

38. Demographic Yearbook of Poland. Central Statistical Office. Warsaw 2011.

39. Andren S, Elmståhl S. The relationship between caregiver burden, caregiver's perceived health and their sense of coherence in caring for elders with dementia. J Clin Nurs 2008; 17: 790-9.

40. Wichowicz HM, Wieczorek D. Screening post-stroke depression using the Hospital Anxiety and Depression Scale. Psychiatr Pol 2011; 45: 505-14.

41. Łuszczynska A, Kowalska M, Mazurkiewicz M, Schwarzer R. Berlin Social Support Scales (BSSS): Polish version of BSSS and preliminary results on its psychometric properties. Psychol Stud 2006; 44: 17-27.

42. Jaracz K, Kalfoss M, Górna K, Bączyk G. Quality of life in Polish respondents: psychometric properties of the Polish WHOQOL-Bref. Scand J Caring Sci 2006; 20: 251-60.

43. Quinn TJ, Langhorne P, Stott DJ. Barthel index for stroke trials: development, properties, and application. Stroke 2011; 42: 1146-51.

44. Gray LJ, Ali M, Lyden PD, Bath PM. Virtual International Stroke Trials Archive Collaboration. Interconversion of the National Institutes of Health Stroke Scale and Scandinavian Stroke Scale in acute stroke. J Stroke Cerebrovasc Dis 2009; 18: 466-8.

45. Puchowska-Florek $M$, Książkiewicz B, Nowaczewska $M$. The evaluation of usefulness of selected scales and tests used to assess aphasia in patients with acute stroke. Interdisciplinary Problems of Stroke 2005; 7: 39-47.

46. Hurwitz EL. Do asthma and physical inactivity influence the associations of personal and job stressors with perceived stress and depression? Findings from the 19981999 California Work and Health Survey. Ann Epidemiol 2003; 13: 358-68.

47. Weintraub D, Saboe K, Stern MB. Effect of age on geriatric depression scale performance in Parkinson's disease. Mov Disord 2007; 22: 1331-5.

48. Rosen BL, DeMaria AL. Statistical significance vs. practical significance: an exploration through health education. Am J Health Educ 2012; 43: 235-49.

49. Thommessen B, Wyller TB, Bautz-Holter E, Laake K Acute phase predictors of subsequent psychosocial burden in carers of elderly stroke patients. Cerebrovasc Dis 2001; 11: 201-6.

50. Lamura G, Mnich E, Nolan M, Wojszel B, Krevers B, Mestheneos L. Family carers' experiences using support ser- vices in Europe: empirical evidence from the EUROFAMCARE Study. The Gerontologist 2008; 48: 752-71.

51. Garces J, Carretero S, Rodenas F, Aleman C. Review of programs to alleviate the burden of informal caregivers of dependent persons. Arch Gerontol Geriatr 2010; 50: 254-9.

52. Greenwood N, Mackenzie A. Informal caring for stroke survivors: meta-ethnographic review of qualitative literature. Maturitas 2010; 66: 268-76.

53. Cooper C, Balamurali TB, Selwood A, Livingston G. A systematic review of intervention studies about anxiety in caregivers of people with dementia. Int J Geriatr Psychiatr 2007; 22: 81-8.

54. Piechowski-Jozwiak B, Bogousslavsky J. Neurobehavioral syndromes. Front Neurol Neurosci 2012; 30: 57-60. 